\title{
Mixed structure Zn(S,O) nanoparticles: synthesis and characterization
}

\author{
Anu Dhupar ${ }^{1}$, Suresh Kumar ${ }^{2, *}$, VAndana Sharma ${ }^{1}$, J.K. Sharma ${ }^{1}$ \\ ${ }^{1}$ Department of Physics, M.M. School of Sciences, Maharishi Markandeshwar (Deemed to be University), Mullana, Ambala, \\ Haryana-133207, India \\ ${ }^{2}$ Department of Physics, Maharishi Markandeshwar University, Sadopur, Ambala, Haryana-134007, India
}

\begin{abstract}
In the present work, mixed structure $\mathrm{Zn}(\mathrm{S}, \mathrm{O})$ nanoparticles have been synthesized using solution based chemical coprecipitation technique. Two different zinc sources $\left(\mathrm{Zn}\left(\mathrm{CH}_{3} \mathrm{COO}\right)_{2} \cdot 2 \mathrm{H}_{2} \mathrm{O}\right.$ and $\left.\mathrm{ZnSO}_{4} \cdot 7 \mathrm{H}_{2} \mathrm{O}\right)$ and one sulfur source $\left(\mathrm{CSNH}_{2} \mathrm{NH}_{2}\right)$ have been used as primary chemical precursors for the synthesis of the nanoparticles in the presence and absence of a capping agent (EDTA). The structural, morphological, compositional and optical properties of the nanoparticles have been analyzed using X-ray diffraction (XRD), scanning electron microscopy (SEM), energy dispersive X-ray spectroscopy (EDX), Fourier transmission infra-red (FT-IR) and UV-Visible (UV-Vis) spectroscopy. XRD revealed the formation of mixed phases of c-ZnS, $\mathrm{h}-\mathrm{ZnS}$ and $\mathrm{h}-\mathrm{ZnO}$ in the synthesized nanoparticles. The surface morphology was analyzed from SEM micrographs which showed noticeable changes due to the effect of EDTA. EDX analysis confirmed the presence of zinc, sulfur and oxygen in $\mathrm{Zn}(\mathrm{S}, \mathrm{O})$ nanoparticles. FT-IR spectra identified the presence of characteristic absorption peaks of $\mathrm{ZnS}$ and $\mathrm{ZnO}$ along with other functional group elements. The optical band gap values were found to vary from $4.16 \mathrm{eV}$ to $4.40 \mathrm{eV}$ for $\mathrm{Zn}(\mathrm{S}, \mathrm{O})$ nanoparticles which are higher in comparison to the band gap values of bulk $\mathrm{ZnS}$ and $\mathrm{ZnO}$. These higher band gap values may be attributed to the mixed structure of $\mathrm{Zn}(\mathrm{S}, \mathrm{O})$ nanoparticles.
\end{abstract}

Keywords: ZnS; ZnO; chemical coprecipitation technique; structural analysis; optical properties

\section{Introduction}

Semiconductor nanoparticles with their novel properties and promising applications in basic research and technology have aroused great interest of the researchers all across the world. The novel properties of these nanoparticles are much different from their corresponding bulk materials arising basically from their high surface-to-volume ratio and quantum confinement effect [1-3]. The nanoscale size of these materials corresponding to quantum regime also enhances the role played by their surface atoms in various physical and chemical processes. The electronic states created at the surfaces strongly affect the physical and chemical properties of these nanomaterials [4]. Thus, the proficiency in modifying their properties by controlling the size and shape of the particles is technologically important $[5,6]$. Furthermore, extensive research has

*E-mail: sureshlakhanpal@gmail.com been practiced on the synthesis and characterization of semiconducting nanoparticles towards their practical applications [7-10].

Zinc based II-IV semiconductors: zinc sulphide $(\mathrm{ZnS})$ and zinc oxide $(\mathrm{ZnO})$ have received much attention in the recent years due to their wide bandgap and envisaged properties [11]. $\mathrm{ZnS}$ is a non-toxic semiconductor with a wide and direct band gap, which can be observed naturally in two structures: cubic (c-ZnS: zinc blende) structure, having the lattice constant, $a=5.409 \AA$ and optical band gap, $\mathrm{E}_{\mathrm{g}}=3.72 \mathrm{eV}$, and hexagonal (h$\mathrm{ZnS}$ : wurtzite) structure, having the lattice constants $\mathrm{a}=\mathrm{b}=3.812 \AA$ and $\mathrm{c}=6.26 \AA$ and $\mathrm{E}_{\mathrm{g}}=3.77 \mathrm{eV}[6,12,13]$. This material is used in detectors, emitters and modulators in optoelectronics, light emitting laser diodes, optical windows for visible and ultraviolet light etc., [14, 15]. It has also been broadly investigated for applications in different disciplines such as photocatalysis, 
solar energy conversion, projection television, fluorescence microscopy etc., [16-19]. Additionally, zinc oxide $(\mathrm{ZnO})$ is one of the most famous IIVI semiconductor due to the large exciton binding energy of $60 \mathrm{meV}$ and a wide band gap of $3.37 \mathrm{eV}$ at room temperature [20]. Normally it crystallizes in a hexagonal (h-ZnO: wurtzite) structure with $\mathrm{a}=\mathrm{b}=3.25 \AA$ and $\mathrm{c}=5.12 \AA$ [20]. It is a promising material for various applications such as ultraviolet light emitters, flat panel displays, spin functional devices, transparent conductive oxides, gas sensors and surface acoustic wave devices [4, 20-22]. There has been much consideration on the synthesis of nanoparticles of both these semiconductors by various techniques which include chemical vapor deposition, thermal evaporation, sol-gel, combustion, hydrothermal, non-hydrolytic high temperature injection method, microwave irradiation, solvothermal, mechanical ball milling, coprecipitation etc., [8, 17, 23-29]. Among these techniques, coprecipitation is a conventional wet chemical technique to synthesize materials with high yield in mass production [2931]. Frequently, in many studies, $\mathrm{ZnS}$ have been synthesized with cubic, hexagonal and polymorph structures, i.e. presence of both cubic and hexagonal phases, [4, 13, 32] whereas $\mathrm{ZnO}$ synthesized normally in hexagonal structure [9-11, 20]. Alternatively, in other studies, simultaneous existence of different phases of $\mathrm{ZnS}$ and $\mathrm{ZnO}$ in the synthesized material have been reported [11, 33]. Various researchers have synthesized mixed structure $\mathrm{ZnS}-\mathrm{ZnO}$ nanocomposites using different wetchemical routes $[3,4]$. It has been observed that $\mathrm{ZnS}$ nanoparticles work as excellent shell coating layers for $\mathrm{ZnO}$ nanoparticles and enhance the optical, photoluminescence and electrical properties of $\mathrm{ZnO}-\mathrm{ZnS}$ nanostructures. The mixed structure formation of nanoparticles may tend to bring considerable changes in the different properties of semiconductor materials [3, 4]. Thus, the aim of this work is to synthesize $\mathrm{Zn}(\mathrm{S}, \mathrm{O})$ nanoparticles via simple coprecipitation technique and to study their structural, morphological and optical properties. However, the influence of ethylenediaminetetraacetic acid (EDTA) as a capping agent for the synthesis of $\mathrm{Zn}(\mathrm{S}, \mathrm{O})$ is also studied in the present work.

\section{Experimental}

\subsection{Coprecipitation synthesis of $\mathrm{Zn}(\mathrm{S}, \mathrm{O})$ nanoparticles}

$\mathrm{Zn}(\mathrm{S}, \mathrm{O})$ nanoparticles were prepared using two different zinc source precursors (zinc acetate: $\mathrm{Zn}\left(\mathrm{CH}_{3} \mathrm{COO}\right)_{2} \cdot 2 \mathrm{H}_{2} \mathrm{O}$ and zinc sulfate: $\left.\mathrm{ZnSO}_{4} \cdot 7 \mathrm{H}_{2} \mathrm{O}\right)$, thiourea $\left(\mathrm{CSN}_{2} \mathrm{H}_{2}\right)$ as a sulfur source, ammonium hydroxide $\left(\mathrm{NH}_{4} \mathrm{OH}\right)$ as a complexing agent and ethylenediaminetetraacetic acid (EDTA) as a capping agent. Analytical grade (AR) reagents, purchased from Merck, India, were used in synthesis of the nanoparticles. In a typical procedure, equimolar $(0.5 \mathrm{M})$ aqueous solutions of zinc source precursors and thiourea were prepared separately in $100 \mathrm{~mL}$ of distilled water under continuous stirring. To synthesize nanoparticles without capping agent, ammonia solution (25\%) was mixed in the aqueous solution of zinc source to maintain the $\mathrm{pH}$ of the solution to be $11.5 \pm 0.5$. Then, thiourea solution was added dropwise to the above mixture under continuous stirring while EDTA $(0.1 \mathrm{M})$ was used in place of ammonia solution to synthesize nanoparticles under the influence of capping agent. The whole mixture was stirred for $3 \mathrm{~h}$ at $60 \pm 5{ }^{\circ} \mathrm{C}$ using a hot plate magnetic stirrer. The precipitates obtained were filtered out and washed several times with acetone and distilled water to remove unwanted impurities. Final products were dried in a hot air oven at $70{ }^{\circ} \mathrm{C}$ for $5 \mathrm{~h}$. The nanoparticles prepared using zinc acetate without and with EDTA are mentioned as sample $\mathrm{Zn}(\mathrm{S}, \mathrm{O})-1$ and $\mathrm{Zn}(\mathrm{S}, \mathrm{O})-1 \mathrm{E}$, respectively. Moreover, the nanoparticles prepared using zinc sulfate without and with EDTA are termed as $\mathrm{Zn}(\mathrm{S}, \mathrm{O})-2$ and $\mathrm{Zn}(\mathrm{S}, \mathrm{O})-2 \mathrm{E}$ respectively.

\subsection{Characterization}

X-ray diffraction (XRD) patterns of the asprepared nanoparticles have been recorded using PANalytical X'Pert PRO diffractometer with $\mathrm{CuK} \alpha$ radiation $(1.5406 \AA$ ), operating at $45 \mathrm{kV}$ and $40 \mathrm{~mA}$ in the $2 \theta$ scanning range from $25^{\circ}$ to $75^{\circ}$. XRD data has further been analyzed for fitting and baseline correction using Origin- 8 software. The morphology investigation and compositional 
analysis of the nanoparticles have been carried out using scanning electron microscope (SEM: JEOLJSM-IT300) equipped with energy dispersive X-ray analyzer (EDX: QUANTAX, BRUKER). FT-IR spectra have been recorded with PerkinElmer spectrometer in transmittance (T) mode using $\mathrm{KBr}$ pellet technique. The optical absorbance (A) and reflection spectra (R) of the nanoparticles have been recorded using UV-Vis spectrophotometer (SCHIMAZDU 2600).

\section{Results and discussion}

\subsection{Structural analysis}

XRD patterns of the synthesized nanoparticles have been presented and indexed in Fig. 1. The formation of multiple diffraction peaks depicts the polycrystalline nature of the nanoparticles. The substantial broadening of reflection peaks may indicate the existence of nanosized particles [31]. Although, the diffuse background in XRD spectrum may indicate the presence of amorphous nature of the nanoparticles [29, 30]. From the XRD peaks analysis, it has been observed that $\mathrm{Zn}(\mathrm{S}, \mathrm{O})$ nanoparticles exhibit mixed structure, i.e. c-ZnS, h-ZnS and $\mathrm{h}-\mathrm{ZnO}$ phases. In the nanoparticles synthesized using zinc acetate, i.e. $\mathrm{Zn}(\mathrm{S}, \mathrm{O})-1$ and $\mathrm{Zn}(\mathrm{S}, \mathrm{O})$ $1 \mathrm{E}$ (Fig. 1), the prominent XRD peaks positioned at $2 \theta(\mathrm{h} \mathrm{k} \mathrm{l})=28.4^{\circ}\left(\begin{array}{lll}1 & 1 & 1\end{array}\right)$ and $33.1^{\circ}$ (2 $\left.\begin{array}{lll}2 & 0\end{array}\right)$ belong to lattice planes of c-ZnS, while $2 \theta(\mathrm{h} \mathrm{k} \mathrm{l})=26.8^{\circ}\left(\begin{array}{lll}1 & 0 & 0\end{array}\right), 39.1^{\circ}\left(\begin{array}{lll}1 & 0 & 2\end{array}\right)$ and $52.3^{\circ}$ (1 03 ) belong to h-ZnS [34, 35]. Further, reflection peaks at $2 \theta(\mathrm{h} \mathrm{k} \mathrm{l})=31.5^{\circ}\left(\begin{array}{lll}1 & 0 & 0\end{array}\right), 34.4^{\circ}\left(\begin{array}{lll}0 & 0 & 2\end{array}\right)$ and $36.3^{\circ}\left(\begin{array}{lll}1 & 0 & 1\end{array}\right)$ belong to h-ZnO [36]. However, the peak at $2 \theta=46.6^{\circ}$ is shared by

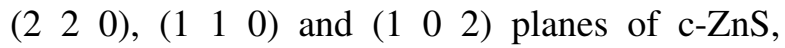
$\mathrm{h}-\mathrm{ZnS}$ and $\mathrm{h}-\mathrm{ZnO}$, respectively. The peak at $2 \theta=59.0^{\circ}$ is shared by $\left(\begin{array}{lll}2 & 2 & 2\end{array}\right)$ and $\left(\begin{array}{lll}0 & 0 & 4\end{array}\right)$ planes of c-ZnS and $\mathrm{h}-\mathrm{ZnS}$ respectively, while $2 \theta=69.2^{\circ}$ by $\left(\begin{array}{lll}4 & 0 & 0\end{array}\right)$ and $\left(\begin{array}{lll}2 & 0 & 1\end{array}\right)$ of $c-$ $\mathrm{ZnS}$ and $\mathrm{h}-\mathrm{ZnO}$, respectively. In the nanoparticles synthesized using precursor zinc sulfate, i.e. $\mathrm{Zn}(\mathrm{S}, \mathrm{O})-2$ and $\mathrm{Zn}(\mathrm{S}, \mathrm{O})-2 \mathrm{E}$ (Fig. 1), the prominent peaks at $2 \theta(\mathrm{h} \mathrm{k} 1)=28.6^{\circ}\left(\begin{array}{lll}1 & 1 & 1\end{array}\right)$ and $33.1^{\circ}\left(\begin{array}{lll}2 & 0 & 0\end{array}\right)$ correspond to $\mathrm{c}-\mathrm{ZnS}$, while
$2 \theta(\mathrm{h} \mathrm{k} \mathrm{l})=39.8^{\circ}\left(\begin{array}{lll}1 & 0 & 2\end{array}\right)$ and $56.8^{\circ}\left(\begin{array}{lll}2 & 0 & 1\end{array}\right)$ belong to $\mathrm{h}-\mathrm{ZnS}$. The reflection peaks at $2 \theta$ $(\mathrm{h} k \mathrm{k})=31.5^{\circ}\left(\begin{array}{lll}1 & 0 & 0\end{array}\right), 36.1^{\circ}\left(\begin{array}{lll}1 & 0 & 1\end{array}\right)$ and $62.9^{\circ}\left(\begin{array}{lll}1 & 0 & 3\end{array}\right)$ are assigned to $\mathrm{h}-\mathrm{ZnO}$. Moreover, the peak at $2 \theta=47.4^{\circ}$ is common to $\left(\begin{array}{lll}2 & 2 & 0\end{array}\right)$, $\left(\begin{array}{lll}1 & 1 & 0\end{array}\right)$ and (lll $\left.\begin{array}{lll}1 & 0 & 2\end{array}\right)$ planes of c-ZnS, h-ZnS and $\mathrm{h}-\mathrm{ZnO}$ respectively. The peak at $2 \theta=58.8^{\circ}$ is

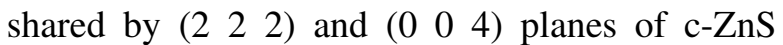
and $\mathrm{h}-\mathrm{ZnS}$ while $2 \theta=69.2^{\circ}$ by $\left(\begin{array}{lll}4 & 0 & 0\end{array}\right)$ and (2 0 1) planes of c- $\mathrm{ZnS}$ and $\mathrm{h}-\mathrm{ZnO}$, respectively. It has been observed that diffraction peaks at $2 \theta(\mathrm{h} \mathrm{k} \mathrm{l})=26.8^{\circ}, 34.4^{\circ}$ and $52.3^{\circ}$ are formed only for $\mathrm{Zn}(\mathrm{S}, \mathrm{O})-1$ and $\mathrm{Zn}(\mathrm{S}, \mathrm{O})-1 \mathrm{E}$ while the peaks at $2 \theta(\mathrm{h} \mathrm{k} \mathrm{l})=56.8^{\circ}$ and $62.9^{\circ}$ exist only for $\mathrm{Zn}(\mathrm{S}, \mathrm{O})$ 2 and $\mathrm{Zn}(\mathrm{S}, \mathrm{O})-2 \mathrm{E}$. This variation in XRD peak patterns may be due to the use of different $\mathrm{Zn}^{2+}$ ion sources in the synthesis process.
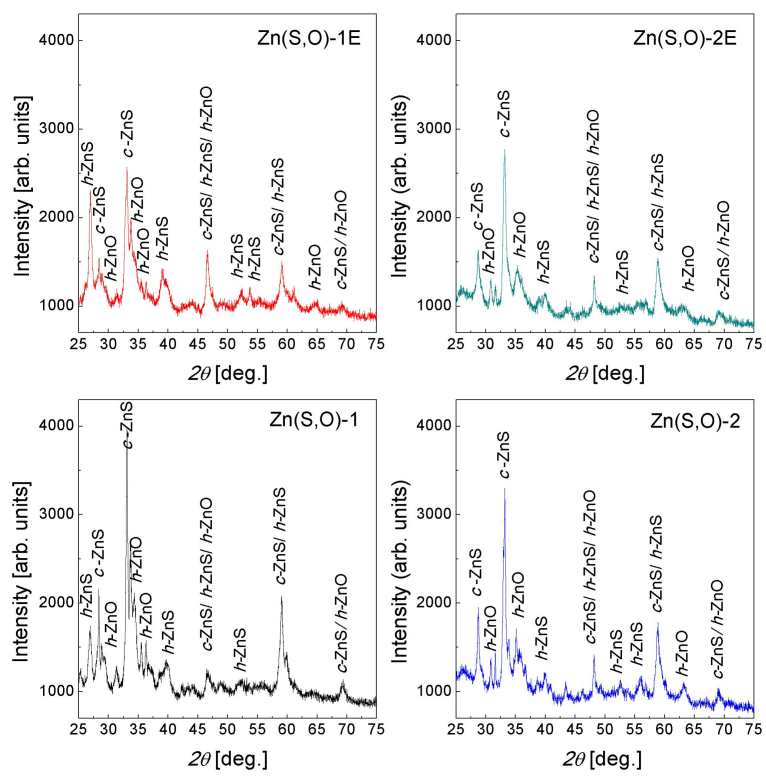

Fig. 1. XRD spectra for $\mathrm{Zn}(\mathrm{S}, \mathrm{O})$ nanoparticles synthesized using zinc acetate (without EDTA: $\mathrm{Zn}(\mathrm{S}, \mathrm{O})-1$ and with EDTA: $\mathrm{Zn}(\mathrm{S}, \mathrm{O})-1 \mathrm{E})$ and zinc sulfate (without EDTA: $\mathrm{Zn}(\mathrm{S}, \mathrm{O})-2$ and with EDTA: Zn(S,O)-2E).

From the XRD analysis, it is clear that many diffraction peaks are shared by different $\mathrm{h} \mathrm{k} l$ values associated with different phases of $\mathrm{ZnS}$ and $\mathrm{ZnO}$. Therefore, it may signify a mixed structure formation in the synthesized $\mathrm{Zn}(\mathrm{S}, \mathrm{O})$ nanoparticles. This type of mixed structure formation in $\mathrm{ZnS}$ 
and $\mathrm{ZnO}$ nanoparticles has been also reported in the literature [3, 4]. It has been also observed that the intensity of XRD peaks in the nanoparticles synthesized using EDTA i.e. $\mathrm{Zn}(\mathrm{S}, \mathrm{O})-1 \mathrm{E}$ and $\mathrm{Zn}(\mathrm{S}, \mathrm{O})-2 \mathrm{E}$ is found to be lower than the intensity of peaks without EDTA, i.e. $\mathrm{Zn}(\mathrm{S}, \mathrm{O})-1$ and $\mathrm{Zn}(\mathrm{S}, \mathrm{O})-2$ (Fig. 1). This may be caused by the interaction of ionic species with the molecules of capping agent during the nucleation and growth process. The capping agent is capable to control the agglomeration of particles which tends to restrict their size in nanoscale range [21]. In case of $\mathrm{Zn}(\mathrm{S}, \mathrm{O})-1$ and $\mathrm{Zn}(\mathrm{S}, \mathrm{O})-1 \mathrm{E}$ samples, the prominent reflection peaks have been identified (Fig. 1) for individual phase of $\mathrm{c}-\mathrm{ZnS}$ with $\mathrm{h} \mathrm{k} 1$ values corresponding to $\left(\begin{array}{lll}1 & 1 & 1\end{array}\right)$ and $\left(\begin{array}{lll}2 & 0 & 0\end{array}\right)$, $\mathrm{h}-\mathrm{ZnS}$ and $\mathrm{h}-\mathrm{ZnO}$ with $\left(\begin{array}{lll}1 & 0 & 0\end{array}\right)$ and $\left(\begin{array}{lll}0 & 0 & 2\end{array}\right)$, for mixed phase of $\mathrm{c}-\mathrm{ZnS} / \mathrm{h}-\mathrm{ZnS} / \mathrm{h}-\mathrm{ZnO}$ with

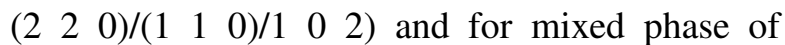
c-ZnS/h-ZnS with $\left(\begin{array}{lll}2 & 2 & 2\end{array}\right) /\left(\begin{array}{lll}0 & 0 & 4\end{array}\right)$. Similarly, for $\mathrm{Zn}(\mathrm{S}, \mathrm{O})-2$ and $\mathrm{Zn}(\mathrm{S}, \mathrm{O})-2 \mathrm{E}$ samples, the identified prominent peaks (Fig. 1) for individual phase of $\mathrm{c}-\mathrm{ZnS}$ with $\mathrm{h} \mathrm{k} \mathrm{l}$ values corresponding to $\left(\begin{array}{lll}1 & 1 & 1\end{array}\right)$ and ( $\left.\begin{array}{lll}2 & 0 & 0\end{array}\right), \mathrm{h}-\mathrm{ZnS}$ and $\mathrm{h}-\mathrm{ZnO}$ with $\left(\begin{array}{lll}1 & 0 & 2\end{array}\right)$ and (1 0 1 1 ), for mixed phase of $\mathrm{c}-\mathrm{ZnS} / \mathrm{h}-\mathrm{ZnS} / \mathrm{h}-\mathrm{ZnO}$

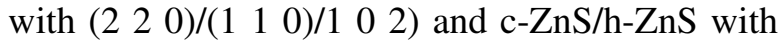
(2 2 2 2)/(l0 04 ) are observed.

The average particle size $\left(D_{h k 1}\right)$ was estimated (Table 1) from these identified XRD peaks using Debye-Scherrer equation [6]:

$$
D_{h k l}=\frac{K \lambda}{\beta_{h k l} \cos \theta_{h k l}}
$$

where $\mathrm{K}$ is shape factor, $\lambda$ is wavelength of $\mathrm{CuK} \alpha$ radiation of $\mathrm{X}$-ray, $\beta$ is full width at half maximum (FWHM) of the prominent peak and $\theta$ is Bragg diffraction angle. The interplanar spacing $\mathrm{d}_{\mathrm{hkl}}$ values have been calculated using Bragg equation (Table 1) and were found to be comparable with reported values [33].

The values of microstrain $\epsilon_{\mathrm{hk} 1}$ and dislocation density $\delta_{\mathrm{hkl}}$ (Table 1 ) caused by crystal imperfections have been calculated $[31,37,38]$. The variation in $D_{h k 1}$ and $d_{h k 1}$ values may be associated with different factors such as surface defects, strain and dislocations [38]. The decrease in $\mathrm{D}_{\mathrm{hkl}}$ and $\mathrm{d}_{\mathrm{hk} 1}$ values for $\mathrm{Zn}(\mathrm{S}, \mathrm{O})-1 \mathrm{E}$ and $\mathrm{Zn}(\mathrm{S}, \mathrm{O})-2 \mathrm{E}$ and corresponding increase in $\epsilon_{\mathrm{hkl}}$ and $\delta_{\mathrm{hkl}}$ values can be associated with the decrease in size of nanoparticles under the influence of EDTA. The high values of microstrain and dislocation density for the samples with EDTA in comparison to the samples without EDTA may be attributed to the presence of defects, lattice mismatch, increase in grain boundaries and stoichiometric deviations that have been promoted by capping agent [39].

\subsection{Morphological and compositional analysis}

The surface topography of $\mathrm{Zn}(\mathrm{S}, \mathrm{O})$ nanoparticles has been investigated using SEM micrographs (Fig. 2). It can be interpreted that synthesized $\mathrm{Zn}(\mathrm{S}, \mathrm{O})$ nanoparticles are in diffused form. They have almost similar morphology for both samples prepared by using different $\mathrm{Zn}^{2+}$ ion sources (Fig. 2: $\mathrm{Zn}(\mathrm{S}, \mathrm{O})-1$ and $\mathrm{Zn}(\mathrm{S}, \mathrm{O})-2)$ which changes with addition of EDTA (Fig. 2: $\mathrm{Zn}(\mathrm{S}, \mathrm{O})-1 \mathrm{E}$ and $\mathrm{Zn}(\mathrm{S}, \mathrm{O})-2 \mathrm{E})$. Nanoparticles without capping agent form solid clusters in which particles are strongly agglomerated and appear as bigger size particles. However, the nanoparticles with capping agent give a scattered view in which agglomeration appears to be suppressed due to the influence of EDTA. The capping agent weakens the interaction between the particles and hence, changes the surface morphology of $\mathrm{Zn}(\mathrm{S}, \mathrm{O})$ nanoparticles.

EDX analysis has been carried out to identify the elemental composition of the synthesized nanoparticles. EDX spectra (Fig. 3) clearly reveal the presence of expected elements zinc, sulfur and oxygen in the samples. It also shows the presence of carbon peak which belongs to carbon coating used in EDX analysis. It has been observed that both, $\mathrm{Zn}(\mathrm{S}, \mathrm{O})-1$ and $\mathrm{Zn}(\mathrm{S}, \mathrm{O})-2$, are found to be rich in oxygen content (at.\%). Moreover, the existence of zinc, sulfur and oxygen peaks also supports the formation of mixed structure of $\mathrm{Zn}(\mathrm{S}, \mathrm{O})$ nanoparticles. Similar type of elemental analysis for oxygen rich $\mathrm{Cr}$ doped $\mathrm{ZnO}$ nanorods having an atomic percentage of $70 \%$ for oxygen, $\sim 23 \%$ for zinc and $\sim 5 \%$ for $\mathrm{Cr}$ has also been reported by researchers [40]. The high oxygen content (at.\%) 
Table 1. Values of average particle size $\mathrm{D}_{\mathrm{hkl}}$, interplanar spacing $\mathrm{d}_{\mathrm{hkl}}$, microstrain $\epsilon_{\mathrm{hkl}}$ and dislocation density $\delta_{\mathrm{hkl}}$ for $\mathrm{Zn}(\mathrm{S}, \mathrm{O})$ nanoparticles.

\begin{tabular}{ccccc}
\hline Sample & $\begin{array}{c}\mathrm{D}_{\mathrm{hkl}} \\
{[\mathrm{nm}]}\end{array}$ & $\begin{array}{c}\mathrm{d}_{\mathrm{hkl}} \\
{[\AA]}\end{array}$ & $\epsilon_{\mathrm{hkl}}=\beta_{\mathrm{hkl}} / 4 \tan \theta$ & $\begin{array}{c}\delta_{\mathrm{hkl}}=1 / \mathrm{D}_{\mathrm{hk}}^{2} \\
{\left[\text { line } / \mathrm{m}^{2}\right]}\end{array}$ \\
\hline \hline $\mathrm{Zn}(\mathrm{S}, \mathrm{O})-1$ & 35.92 & 2.263 & $2.83 \times 10^{-3}$ & $1.06 \times 10^{15}$ \\
$\mathrm{Zn}(\mathrm{S}, \mathrm{O})-1 \mathrm{E}$ & 33.31 & 2.258 & $3.78 \times 10^{-3}$ & $2.11 \times 10^{15}$ \\
$\mathrm{Zn}(\mathrm{S}, \mathrm{O})-2$ & 37.92 & 2.190 & $2.74 \times 10^{-3}$ & $1.08 \times 10^{15}$ \\
$\mathrm{Zn}(\mathrm{S}, \mathrm{O})-2 \mathrm{E}$ & 33.41 & 2.167 & $3.22 \times 10^{-3}$ & $1.55 \times 10^{15}$ \\
\hline
\end{tabular}

in the synthesized nanoparticles may be attributed to the presence of moisture content as a result of traces of acetone and water which are used in the washing of nanoparticles. This may also be verified by the presence of strong and broad peaks of $\mathrm{H}_{2} \mathrm{O}$ vibration in FT-IR spectra (Fig. 4).

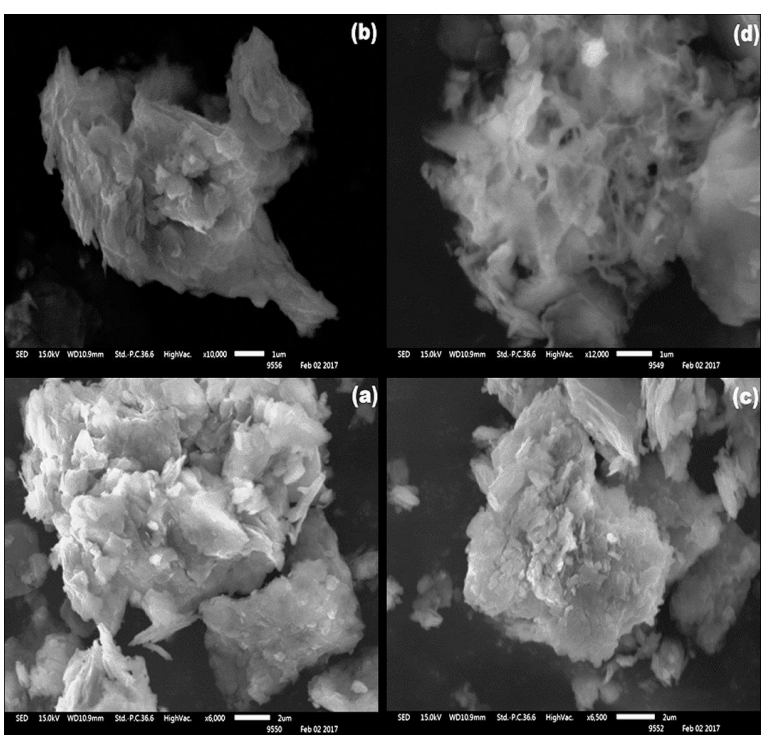

Fig. 2. SEM images of $\mathrm{Zn}(\mathrm{S}, \mathrm{O})$ nanoparticles prepared using zinc acetate, (a) and (b), and zinc sulfate, (c) and (d), without and with EDTA.

\subsection{FT-IR analysis}

FT-IR is used to detect the presence of any functional group or adsorbed chemical species in the prepared material. FT-IR spectra (Fig. 4) show different infrared (IR) absorption bands and peaks corresponding to vibration modes present in the synthesized nanoparticles. In all the samples, a broad band situated at $\sim 3376 \mathrm{~cm}^{-1}$ may

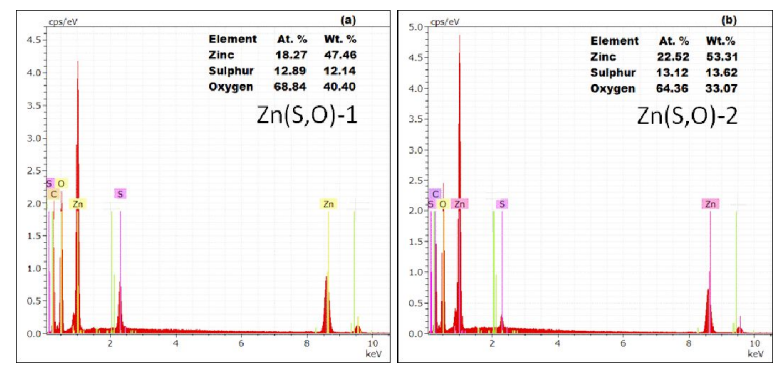

Fig. 3. EDX spectra for $\mathrm{Zn}(\mathrm{S}, \mathrm{O})-1$ and $\mathrm{Zn}(\mathrm{S}, \mathrm{O})-2$ nanoparticles.

be attributed to normal stretching of $-\mathrm{OH}$ group. This may indicate the presence of moisture content in the synthesized particles. The broad band positioned at $\sim 2110 \mathrm{~cm}^{-1}$ can be assigned to $\mathrm{N}=\mathrm{C}$ stretching or isothiocynate $(-\mathrm{NCS})$ formed during synthesis process because of hydrolysis of thiourea.

In the nanoparticles synthesized using zinc acetate $(\mathrm{Zn}(\mathrm{S}, \mathrm{O})-1$ and $\mathrm{Zn}(\mathrm{S}, \mathrm{O})-1 \mathrm{E}), \mathrm{C}=\mathrm{O}$ stretching frequency at $1621.39 \mathrm{~cm}^{-1}$ and $\mathrm{C}-\mathrm{O}$ frequency at $1397 \mathrm{~cm}^{-1}$ are observed for $\mathrm{Zn}(\mathrm{S}, \mathrm{O})-1$ and $\mathrm{Zn}(\mathrm{S}, \mathrm{O})-1 \mathrm{E}$, respectively, indicating $-\mathrm{COOH}$ group [31]. The absorption peak at $1253 \mathrm{~cm}^{-1}$ in $\mathrm{Zn}(\mathrm{S}, \mathrm{O})-1$ belongs to $\mathrm{N}-\mathrm{H}$ stretching corresponding to $\mathrm{NH}_{4} \mathrm{OH}$. The peak at $1544.20 \mathrm{~cm}^{-1}$ in $\mathrm{Zn}(\mathrm{S}, \mathrm{O})-1 \mathrm{E}$ which is absent in $\mathrm{Zn}(\mathrm{S}, \mathrm{O})-1$, can be assigned to the asymmetric stretching of $\mathrm{N}-\mathrm{O}$ mode showing the traces of EDTA and the peak at $2674.82 \mathrm{~cm}^{-1}$ has been assigned to vibrations of $-\mathrm{CH}$ group. The characteristic peaks of $\mathrm{ZnS}$ can be perceived at $\sim 617 \mathrm{~cm}^{-1}$ and $\sim 1110 \mathrm{~cm}^{-1}$ in both $\mathrm{Zn}(\mathrm{S}, \mathrm{O})-1$ and $\mathrm{Zn}(\mathrm{S}, \mathrm{O})-1 \mathrm{E}$ nanoparticles which match with the reported literature $[6$, 31]. Moreover, the spectral peaks at $500 \mathrm{~cm}^{-1}$ 


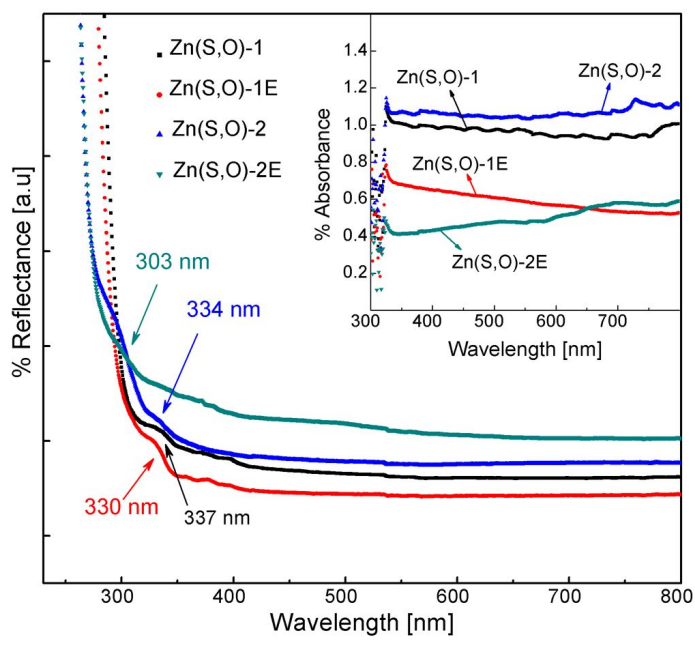

Fig. 4. FT-IR spectra for $\mathrm{Zn}(\mathrm{S}, \mathrm{O})$ nanoparticles synthesized using zinc acetate (without EDTA: $\mathrm{Zn}(\mathrm{S}, \mathrm{O})-1$ and with EDTA: $\mathrm{Zn}(\mathrm{S}, \mathrm{O})-1 \mathrm{E})$ and zinc sulfate (without EDTA: $\mathrm{Zn}(\mathrm{S}, \mathrm{O})-2$ and with EDTA: Zn(S,O)-2E).

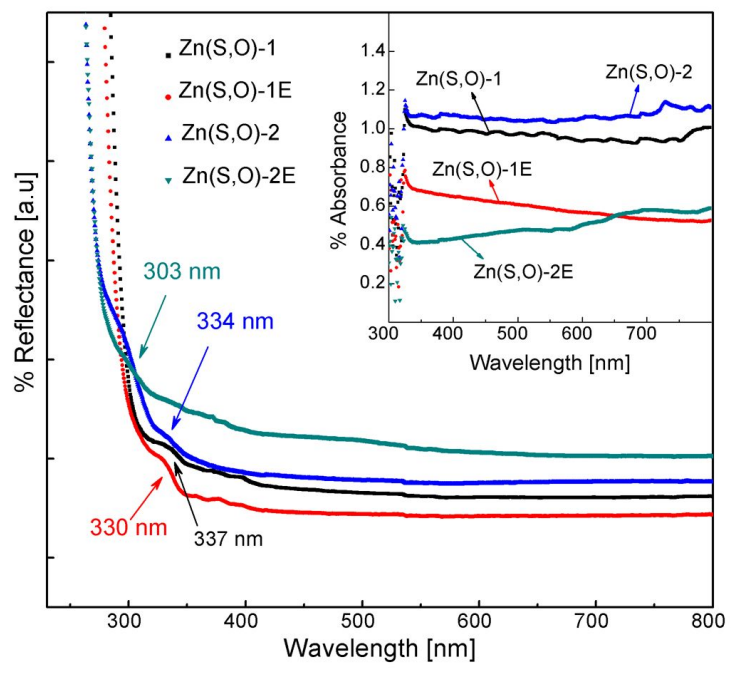

Fig. 5. Diffuse reflectance spectra of $\mathrm{Zn}(\mathrm{S}, \mathrm{O})$ nanoparticles. The inset shows the absorption spectra of $\mathrm{Zn}(\mathrm{S}, \mathrm{O})$ nanoparticles.

in $\mathrm{Zn}(\mathrm{S}, \mathrm{O})-1$ and $521.71 \mathrm{~cm}^{-1}$ in $\mathrm{Zn}(\mathrm{S}, \mathrm{O})-1 \mathrm{E}$ are attributed to $\mathrm{Zn}-\mathrm{O}$ stretching vibrations [3]. An additional peak near $1415 \mathrm{~cm}^{-1}$ in $\mathrm{Zn}(\mathrm{S}, \mathrm{O})$ 1 can be attributed to $\mathrm{Zn}-\mathrm{O}$ deformations [3]. In the nanoparticles synthesized using zinc sulfate (Fig. 4: $\mathrm{Zn}(\mathrm{S}, \mathrm{O})-2$ and $\mathrm{Zn}(\mathrm{S}, \mathrm{O})-2 \mathrm{E})$, the absorption peaks at $1636.63 \mathrm{~cm}^{-1}$ and $1398.28 \mathrm{~cm}^{-1}$ belong to $\mathrm{O}-\mathrm{H}$ stretching vibration of water molecules and $\mathrm{S}=\mathrm{O}$ stretch of sulfate, respectively. The absorption peak at $1253 \mathrm{~cm}^{-1}$ in $\mathrm{Zn}(\mathrm{S}, \mathrm{O})-2$ corresponds to $\mathrm{N}-\mathrm{H}$ stretching mode of thiourea and ammonia. A strong absorption peak at $1545.20 \mathrm{~cm}^{-1}$ in $\mathrm{Zn}(\mathrm{S}, \mathrm{O})-2 \mathrm{E}$ may be attributed to $\mathrm{N}-\mathrm{O}$ stretching indicating the traces of EDTA. The influence of EDTA on nanoparticle synthesis is also evident from the recorded FT-IR spectra. The peaks positioned near $\sim 650 \mathrm{~cm}^{-1}$ and $1015 \mathrm{~cm}^{-1}$ are assigned to $\mathrm{Zn}-\mathrm{S}$ stretching frequency mode for both samples [6]. Moreover, the absorption peaks at $515.86 \mathrm{~cm}^{-1}$ in $\mathrm{Zn}(\mathrm{S}, \mathrm{O})-2$ and $518.80 \mathrm{~cm}^{-1}$ in $\mathrm{Zn}(\mathrm{S}, \mathrm{O})-2 \mathrm{E}$ are assigned to $\mathrm{Zn}-\mathrm{O}$ stretching vibrations. The occurrence of relevant absorption peaks and bands, is connected with the precursors used in the synthesis process, and coexistence of $\mathrm{ZnS}$ and $\mathrm{ZnO}$ peaks may also be an indication for the formation of mixed structure in $\mathrm{Zn}(\mathrm{S}, \mathrm{O})$ nanoparticles.

\subsection{Optical analysis}

Optical behavior is one of the important characteristics of semiconductors. The diffuse reflection spectra (Fig. 5) of the synthesized samples have been recorded at room temperature. It has been observed that, for all samples, reflectance (R) gradually decreases with the increase of wavelength in UV region while, in the visible region it becomes almost constant. $\mathrm{Zn}(\mathrm{S}, \mathrm{O})-1$ nanoparticles exhibit relatively low reflectance among all nanoparticles with an absorption edge at $337 \mathrm{~nm}$. For $\mathrm{Zn}(\mathrm{S}, \mathrm{O})-1 \mathrm{E}$ nanoparticles, a shift in absorption edge to $330 \mathrm{~nm}$ i.e., toward lower wavelength side has been observed. However, for $\mathrm{Zn}(\mathrm{S}, \mathrm{O})$ 2 nanoparticles, the absorption edge observed at $334 \mathrm{~nm}$ is also shifted to $303 \mathrm{~nm}$ for $\mathrm{Zn}(\mathrm{S}, \mathrm{O})$ 2E. Likewise, the absorbance (A) is observed to be higher for $\mathrm{Zn}(\mathrm{S}, \mathrm{O})-1$ and $\mathrm{Zn}(\mathrm{S}, \mathrm{O})-2$ in comparison to $\mathrm{Zn}(\mathrm{S}, \mathrm{O})-1 \mathrm{E}$ and $\mathrm{Zn}(\mathrm{S}, \mathrm{O})-2 \mathrm{E}$ (inset of Fig. 5). This trend in $\mathrm{R}$ and A may be due to the effect of EDTA on the formation of nanoparticles during the synthesis process.

Normally, bulk forms of c-ZnS, h-ZnS and h$\mathrm{ZnO}$ semiconductors have direct optical band gap. However, some alteration in absorption edge have been found due to the crystal size, imperfections, 
defects and mixed structure formation [1]. The lower gradient of the slope in R spectra (Fig. 5) for all samples can be connected with this alteration. The optical band gap of $\mathrm{Zn}(\mathrm{S}, \mathrm{O})$ nanoparticles has been estimated by Kubelka-Munk equation [6] as:

$$
(F(R) h v)^{p}=B\left(h v-E_{g}\right)
$$

where $F(R)=(1-R)^{2} / 2 R$ is Kubelka-Munk function, $\mathrm{R}$ is percentage of reflected light, $\mathrm{h} v$ is the incident photon energy, $\mathrm{B}$ is a constant depending on the transition probability and $\mathrm{p}$ is the power index associated with the optical absorption process. The value of this index depends upon the type of transition i.e., $1 / 2$ for allowed indirect transition and 2 for allowed direct transition [6, 31]. The energy band gap values (Fig. 6) have been determined by extrapolating the linear portion of Kubelka-Munk curves to $\mathrm{x}$-axis. The direct band gap values are found to be $4.16 \mathrm{eV}$ and $4.22 \mathrm{eV}$ for $\mathrm{Zn}(\mathrm{S}, \mathrm{O})-1$ and $\mathrm{Zn}(\mathrm{S}, \mathrm{O})-$ $1 \mathrm{E}$, respectively while, $4.40 \mathrm{eV}$ for both $\mathrm{Zn}(\mathrm{S}, \mathrm{O})-2$ and $\mathrm{Zn}(\mathrm{S}, \mathrm{O})-2 \mathrm{E}$ nanoparticles. It has been analyzed that these band gap values are larger than the values of bulk $\mathrm{ZnS}$ and $\mathrm{ZnO}$ separately [1, 3]. However, the dependence of band gap values on the particle size in nanoregime, i.e. quantum size effect is not clearly justified in the present study. Hence, we can conclude that the possible reason for these large band gap values may be associated with the mixed structure of $\mathrm{Zn}(\mathrm{S}, \mathrm{O})$ nanoparticles.

\section{Conclusions}

$\mathrm{Zn}(\mathrm{S}, \mathrm{O})$ nanoparticles have been synthesized by coprecipitation technique using thiourea as a sulfur source, zinc acetate and zinc sulfate as zinc sources in the presence and absence of EDTA capping agent. XRD studies revealed the formation of a mixed structure in $\mathrm{Zn}(\mathrm{S}, \mathrm{O})$ nanoparticles having $\mathrm{c}-\mathrm{ZnS}, \mathrm{h}-\mathrm{ZnS}$ and $\mathrm{h}-\mathrm{ZnO}$ phases. The average particle size for all synthesized particles was found to be in nanorange which lies between $33 \mathrm{~nm}$ to $38 \mathrm{~nm}$. SEM micrographs displayed a diffused surface morphology of the nanoparticles which changed due to the role played by EDTA in the synthesis process. EDX spectra showed the presence of $\mathrm{Zn}, \mathrm{S}$ and $\mathrm{O}$ elements in the synthesized

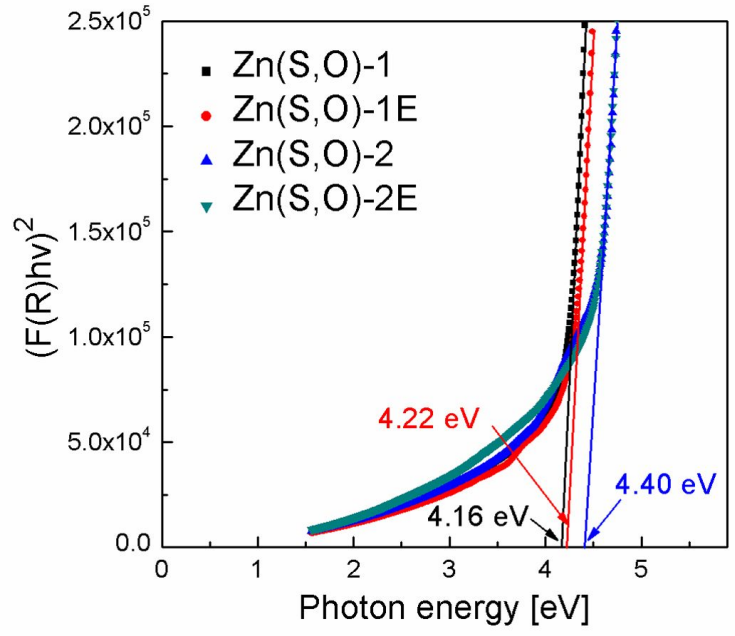

Fig. 6. Kubelka-Munk plots for the direct band gap transition in $\mathrm{Zn}(\mathrm{S}, \mathrm{O})$ nanoparticles.

nanoparticles. FT-IR spectra revealed the characteristic peaks of $\mathrm{ZnS}$ and $\mathrm{ZnO}$ in addition to other relevant absorption peaks of precursors used in the synthesis. The optical study confirmed the formation of mixed structure $\mathrm{Zn}(\mathrm{S}, \mathrm{O})$ nanoparticles as higher band gap values, not justified by quantum size effect, were observed.

\section{Acknowledgements}

The authors acknowledge SAIF, Panjab University Chandigarh for providing SEM, XRD, FT-IR and UV-Vis spectrophotometer facilities and Institute of Nano Science and Technology (INST), Mohali, for SEM (EDX) facility.

\section{References}

[1] Ren G., Lin Z., Wang C., LiU W., Zhang J., Huang F., Liang J., Nanotechnology, 18 (2007), 35705.

[2] Zeng X., Zhang J., Huang F., J. Appl. Phys., 111 (2012), 123525.

[3] Raleaooa R.V., Roodt A., Mhlongo G.G., MoTAUNG D.E., KRoON R.E., NTWAEABorwa O.M., Physica B, 507 (2017), 13

[4] Murugadoss G., J. Lumin., 132 (2012), 2521.

[5] Yoffe A.D., Adv. Phys., 42 (1993), 173.

[6] Reddy D.A., LiU C., Vijayalakshmi R.P., Reddy B.K., J. Alloy. Compd., 582 (2014), 257.

[7] ADAChi D., HAMA T., TOYAMA T., OKaMoto H., $J$. Mater. Sci. Mater. El., 20 (2009), S130.

[8] Wang X., Zhang Q., Zou B., Lei A., Ren P., Appl. Surf. Sci., 257 (2011), 10898

[9] QIU X., Li G., Sun X., LI L., FU X., Nanotechnology, 19 (2009), 215703. 
[10] Jiang H., Hu J., Gu F., Li C., Nanotechnology, 20 (2009), 055706.

[11] Patel P.C, Ghosh S., Srivastava P.C., Mater. Res. Bull., 81 (2016), 85.

[12] Pan S, LiU X., J. Solid State Chem., 191 (2012), 51.

[13] BISWAS S., KAR S., Nanotechnology, 19 (2008), 045710.

[14] Sambasivam S., Joseph D.P., LIN J.G., Venkateswaran C., J. Solid State Chem., 182 (2009), 2598.

[15] Bhargava R.N., Gallagher D., Phys. Rev. Lett., 72 (1994), 3.

[16] Kuppayee M., Nachiyar G.K.V., Ramasamy V., Appl. Surf. Sci., 257 (2011), 6779.

[17] Kimi M., Yuliati L., Shamsuddin M., J. Nanomater., 2015 (2015), 195024.

[18] KUMAR C.S.S.R., Semiconductor Nanomaterials, Wiely-VCH, New York, 2010.

[19] Al-Rasoul K.T., Abbas N.K., Shanan Z.J., Int. J. Electrochem. Sci., 8 (2013), 5594.

[20] RaOufi D., Renew. Energy., 50 (2013), 932.

[21] Wu Y.L., ToK A.I.Y., BoeY F.Y.C., Zeng X.T., Zhang X.H., App. Surf. Sci., 253 (2007), 5473.

[22] Sharma G., Han S.D., Kim J.D., KhatKar S.P., RHEE Y.W., Mater. Sci. Eng. B-Adv., 131 (2006), 271.

[23] Masala O., Seshadri R., Annu. Rev. Mater. Res., 34 (2004), 41.

[24] Pan Y., Yu J., Hu Z., Li H., Cui Q., Zou G., J. Mater. Sci. Technol., 23 (2007), 2.

[25] Ahmadi R., SAdrnezhad S.K, Zangeneh R.N., OGHABIAn M.A., Mater. Sci.-Poland, 34 (2016), 260.
[26] Kucokomeroglu T., Bacaksiz E., Terzioglu C. VARILCI A., Thin Solid Films, 516 (2008), 2913

[27] Topol A.W., Dunn K.A., Barth K.W., Nuesca G.M., TAYlor B.K., DovidenKo K., Kaloyeros A.E., Tuenge R.T., King C.N., J. Mater. Res., 19 (2004), 697.

[28] IPPEn C., Greco T., Kim Y., Kim J., OH M.S., HAN C.J., Wedel A., Org. Electron., 15 (2014), 126.

[29] Kumar S., Sharma J.K., Mater. Sci.-Poland, 34(2016), 368.

[30] Tan C., Zhang H., Nat. Comm., 6 (2015), 7873.

[31] Iranmanesh P., SaEednia S., Nourzpoor M., Chin. Phys. B., 24 (2015), 046104.

[32] BISWAS S., KAR S., Nanotechnology, 19 (2008), 045710.

[33] Murugadoss G., Ramasamy V., Spectrochimica Acta A, 93 (2012), 290.

[34] AMCSD (database code-0018098).

[35] AMCSD (database code-0005074).

[36] AMCSD (database code-0015176).

[37] Bindu P., Thomas S., J. Theor. Appl. Phys., 8 (2014), 123.

[38] Kumar S., Sharma P., Sharma V., Electron. Mater. Lett., 9 (2013), 371.

[39] Hone F.G., DeJene F.B., J. Mater. Res. Technol., (2018), (article in press).

[40] Vijayalakshmi K., Sivaraj D., RSC Adv., 5 (2015), 68461.

Received 2018-04-26 Accepted 2018-10-20 